Castellani Brian (Orcid ID: 0000-0002-8763-8052)

Understanding Comorbid Depression/Physical Health Trajectories

\title{
Exploring Comorbid Depression and Physical Health Trajectories: A Case-Based Computational Modeling Approach
}

\author{
Brian Castellani, ${ }^{a}$ Frances Griffiths ${ }^{b}$, Rajeev Rajaram ${ }^{c}$, Jane Gunn ${ }^{\mathrm{d}}$
}

a. Department of Sociology, Durham University, UK; Department of Psychiatry, Northeastern Ohio Medical University, USA.

b. Division of Health Sciences, University of Warwick, UK; University of the Witwatersrand, Johannesburg, ZA

c. Department of Mathematics, Kent State University, USA. d. Department of General Practice, University of Melbourne, AU.

\section{CORRESPONDING AUTHOR}

Brian Castellani, Ph.D.

Professor of Sociology

Durham University, UK

Adjunct Professor of Psychiatry

Northeastern Ohio Medical University

Rootstown, USA

bcaste13@kent.edu

This is the author manuscript accepted for publication and has undergone full peer review but has not been through the copyediting, typesetting, pagination and proofreading process, which may lead to differences between this version and the Version of Record. Please cite this article as doi: 10.1111/jep.13042

This article is protected by copyright. All rights reserved. 


\begin{abstract}
While comorbid depression/physical health is a major clinical concern, the conventional methods of medicine make it difficult to model the complexities of this relationship. Such challenges include cataloging multiple trends, developing multiple complex etiological explanations, and modeling the collective large-scale dynamics of these trends. Using a case-based complexity approach, this study engaged in a richly-described case study to demonstrate the utility of computational modeling for primary care research. $\mathrm{N}=259$ people were subsampled from the diamond database, one of the largest primary care depression cohort studies worldwide. A global measure of depressive symptoms (PHQ-9) and physical health (PCS-12) were assessed at 3, 6, 9 and 12 months and then annually for a total of seven years. Eleven trajectories and two large-scale collective dynamics were identified; revealing that, while depression is comorbid with poor physical health, chronic illness is often low dynamic and not always linked to depression. Also, some of the cases in the unhealthy and oscillator trends remain ill without much chance of improvement. Finally, childhood abuse, partner violence, and negative life events generally increase across trends. Computational modeling offers a major advance for health researchers to account for the diversity of primary care patients and for developing better prognostic models for team-based interdisciplinary care.
\end{abstract}

KEY WORDS: Comorbid depression and physical health, primary care, complexity theory, longitudinal analysis, nonlinear dynamics, case-based modeling, artificial intelligence, cluster analysis, differential equations. 


\section{INTRODUCTION}

Making clinical sense of the comorbid evolution of depressive symptoms and physical health in primary care is a major concern given their consistent association [1-6]. For example, a cross-sectional review of 1.7 million primary care patients (18 or older) found that over $68.3 \%$ of depressed patients $(10 \%$ of total sample, mean $=52.7$ years $)$ had at least one comorbid health condition [7] - compared with the rest of the sample (non-depressed, mean $=47.5$ years), which had a $41.1 \%$ comorbid physical condition . Also, a 10 year longitudinal study suggested that for men, perceived poor health and chronic illness at baseline was associated with a higher risk of developing depression symptoms [8]. Further, in some instances physical health interacts with the co-existence of depression, often resulting in worse health outcomes and an increased burden on provision and cost of health care $[9,10-15]$.

Despite these recent insights, research into the comorbid evolution of depression/physical health continues to deal with two key challenges [16]. The first is clinical and the second is methodological.

The clinical challenge is that, while the temporal evolution of depression and physical health is often comorbid, this relationship is not singular in its etiological pattern, but is 
multiple and etiologically complex $[17,18]$. For example, a review of these interactions suggests that chronic physical illness can sometimes cause depression through physiological mechanisms [19], particularly changes in allostatic load or the amount of pain experienced or other psychological mechanisms [20]. Changes in social circumstances due to disability are also a causal mechanism, although social support modifies this effect [21]. Furthermore, for many chronic health conditions, where people have concurrent depression, there is no evidence of improvement in the physical condition if the depression is treated [19], although pain may be better controlled and quality of life may improve if depressive symptoms are reduced. For example, for people living with arthritis who are also depressed, treatment of depression with medication and/or psychological therapy improved pain, function and quality of life [22]. There is also evidence that depression can predate and increase risk of developing a range of chronic illnesses; and underlying physiological mechanisms have been identified for this [19]. In turn, however, there are cases where patients with chronic illness do not have a comorbid mental health condition, as in the case of depression.

In short, it appears that not only is the co-morbid relationship between depressive symptoms and physical health based on different complex combinations of sociodemographic and clinical factors; this relationship also evolves along multiple and different trajectories; and in some instances, as in the case of some chronic illnesses, there may be no significant negative relationship at all [23-25]. The challenge for the current literature, therefore, is to engage in a series of exploratory analyses to create a catalogue of these multiple comorbid trajectories, particularly for primary care? And, in turn, to explore what differences in their complex etiologies account for them? All of which takes us to the issue of method. 
The methodological challenge is that, while significant advance has been made in primary care and mental health and clinical evaluation research, the study of the complexities of comorbid depression and physical health continues to be beset by a number of methodological challenges $[2,16,24]$. On the one hand there is the issue of data. As discussed in $[1,2,24]$, most studies in the field focus on clinical depression rather than depressive symptoms in general and emphasize specific populations instead of the diverse range of patients in primary care. Research also tends to be cross-sectional; and, when longitudinal, the number of time-stamps examined is often too low or too spread out. Also, greater emphasis needs to be placed on the continuous (as opposed to discrete) changes in these comorbid trajectories [23].

On the other hand, there is the current methodological mindset of the clinical and mental health fields and the conventions of their statistical techniques. For example, as of 2018 the vast majority of primary care, clinical evaluation and mental health journals have yet to advocate for (and very seldom publish) studies that employ the latest advances in computational methods and complex systems thinking [26 - 28]. In contrast, these same computational methods and systems approaches are being used widely in other scientific fields, including biomedical and health systems research - mainly because they address the aforementioned clinical and methodological limitations [30-35]. Because of their power, these methods are also used daily to run the cyber-infrastructure world(s) in which we all now live; including the ever-growing smart machinery upon which contemporary healthcare depends, from MRIs and diagnostic software to surgical robotics and medical informatics to the nudgewear used to change health behaviors $[23,26,29,30]$.

Examples of these new computational methods include artificial intelligence, machine learning, systems mapping, visual complexity, genetic algorithms, complex network analysis, agent-based modeling, and dynamical systems modeling [26, 29,30]. For those 
interested in an intuitive introduction to these methods, see the following map of the complexity sciences (http://www.art-sciencefactory.com/complexity-map_feb09.html).

Amongst these computational methods, of significant note for clinical evaluation research is the approach known as case-based complexity [26,27]; and, more specifically the Sociology and Complexity Science Toolkit [23, 31-35] - which is specifically useful for modeling multiple comorbid trends across time, particularly those that are high dynamic, as in the case of severe depression. Given the SACS Toolkit's utility for such inquiries, we used it for the current study.

\subsection{Case-Based Computational Modeling}

The SACS Toolkit is an established case-based, computationally grounded, mixed methods framework for modeling complex topics [34,35]. It is part of the wider methodological field of study known as case-based complexity and case-comparative methods, specifically qualitative comparative analysis (QCA) [26,27].

Given its computational approach, however, the SACS Toolkit provides some useful advantages over QCA, growth mixture modeling (GMM) and other statistical methods $[23,25]$. To begin, as already suggested, the SACS Toolkit allows comorbid depressionphysical health trajectories to be studied as continuous (as opposed to discrete), so that not only is the modeling process focused on how trends differ, but also on how trends change across time, particularly when high-dynamic, as in the case of severe depression. To do so, it employs a novel combination of case-comparative method in conjunction with vector quantization, genetic algorithms, ordinary differential equations (ODE) and nonequilibrium statistical mechanics, specifically transport theory and the continuity (advection) partial differential equation (PDE). Second, rather than fitting comorbid depressive symptoms and physical health to a function - as is done in GMM - the SACS 
Toolkit fits its complex functions to these trajectories, which allows for the type of highly refined curve fitting shown in Figures 1 and 2 later in the paper, as well as the identification of minor (small size) and major trends. The result is a multi-step, multilevel procedure for transforming the nonlinear dynamics of complex trajectories into cases, clusters, and densities. In the current paper, we provide a quick step-by-step overview of how we used the SACS Toolkit in the current study, sufficient for readers to gain an appreciation of this approach. (For those interested in a complete overview, see http://www.art-sciencefactory.com/cases.html.)

\subsection{Case Study: The Diamond Cohort}

In addition to employing the SACS Toolkit, the current study examined a subsample of the diamond prospective longitudinal study [24] - which explores the natural history of depressive symptoms over time. Diamond was useful because it is informed by a social model of depressive symptoms and physical health insomuch as it examines the etiological role that clinical, socio-demographic (marital status, age, drug usage, abuse history, etc.) and health service factors (mental health treatment received, current medications, etc.) play in depressive symptoms and chronic illness - which we explored in the current study [36-38]. We also chose this database because it one of the largest primary care depression cohort studies worldwide; and because it addresses many of the aforementioned methodological challenges, including (a) studying persistent depressive symptoms in general (from sub-syndromal to clinical depression) and (b) conducting a longitudinal assessment at 3, 6, 9 and 12 months and then an annual follow-up for a total of seven years - see Methods for details.

\subsection{Research Questions}


Given our methodological and clinical concerns, for our study we sought to explore the following four research questions:

- First, what are the major and minor trends along which comorbid depressive symptoms and physical health evolve?

- Second, are there trends where depression and physical health are not comorbid? For example, do any such trends exist where chronic illness is not positively correlated with high rates of depression or clinical depression? Or, alternatively, are there instances where clinical depression is not associated with chronic illness or significant negative physical health?

- Third, when examined together, do these trends exhibit any large-scale collective dynamics? For example, are there large-scale similarities amongst certain trends that cannot be identified when looking at the individual trajectories alone?

- Finally, what combination of clinical and socio-demographic factors account for the different trends identified or large-scale collective dynamics?

\subsection{Methodological Caveat}

Before proceeding to our methods, we need to clarify a few things. First, the current study, while inferential in nature, was primarily exploratory (as opposed to confirmatory). That is, while we made descriptive claims for what appeared to be key comorbid trends, along with their collective large-scale dynamics and their corresponding complex etiology, our tentative conclusions require further replication. We also acknowledge, as discussed in 2.3 below, that in order to model the dynamics of multiple comorbid depression and physical health trends across time, we required a complete subsample $(\mathrm{N}=259)$ for all time-points of the diamond study $(\mathrm{N}=789)$. As such, further inquiry may be useful to explore the entire dataset for other trends - however, as discussed in 2.4 below, our baseline results were similar to those found in the missing data. Finally, to demonstrate the importance that complexity science gives to minor (long-tail) trends, we 
also explored the small-n trajectories typically treated by conventional health research as outliers, mainly in order to identify high-dynamic minor trends that would be otherwise missed. As such, these trends, while providing important insights, may not be replicable in other studies, given that, while vetted by expert analysis, they are the result of cluster analysis and unsupervised machine intelligence, and could be therefore a statistical artifact.

\section{METHODS}

\subsection{Design and Clinical Setting}

As stated in 1.2, this study used the diamond database [36-38], which was created by recruiting subjects in 2005 in Victoria, Australia from a group of 30 randomly selected family practices, ranging from small private practices to multidisciplinary community health centers. Time stamps included initial assessment $(\mathrm{t}=0)$, and then follow up at $\mathrm{t}=$ 3, 6, 9 and 12 months and then annually for seven years. The University of Melbourne's Human Research Ethics Committee approved the diamond study and consent to publish (Reference number: 030613X). For the current study, we examined all eleven timestamps.

\subsection{Enrollment, Retention and Subsample}

Subjects were eligible for the study if they scored a 16 or higher on the well-known Center for Epidemiological Studies-Depression (CES-D) and read English - see [37] for details. Of the $\mathrm{N}=789$ subjects that were provided informed consent, $\mathrm{N}=129(16.3 \%)$ were lost to follow-up between 3 and 12 months - a common problem for communitybased cohort studies - dropping the total to $\mathrm{N}=449$ subjects. Diamond's dropout for the first year nonetheless compared favorably to similar studies [39].

\subsection{Justification for and Validity of Current Sample}


As mentioned in 1.4, the justification in the current study for reducing the diamond sample to $\mathrm{N}=259$ cases was based on its exploratory (albeit inferential) purpose: we sought to examine complete longitudinal data to gain new insights into how global measures of comorbid depression and physical health co-evolve differently across time. Furthermore, we sought to examine continuous (as opposed to discrete) change, which also required that our data be complete at all sample points. Finally, given that we also explored the larger vector field formed by these multiple trajectories, again complete interpolated data were necessary. For more on these data requirements, see [23].

\section{< INSERT TABLE 1 ABOUT HERE >}

Still, as shown in Table 1, the $\mathrm{N}=259$ subsample was, overall, satisfactorily similar to the original $\mathrm{N}=789$ cohort in [24], with the following differences highlighted. The current subsample was slightly less educated, had a higher rate of marriage, was less likely supported by a pension, slightly more employed, significantly lower in current smoking, and self-assessed health status was slightly better on the lower end of things (fair/poor health). The current subsample was also slightly lower on number of participants having been told they are depressed by a doctor. And yet the subsample had the same number of participants taking anti-depressants and anti-anxiety medications as in the cohort and had almost the exact same CES-D baseline scores for depression. Also, the subsample and cohort were similar in terms of physical health. Still, caution needs to be given to any argument that the current study constitutes anything more than a working catalogue which requires further corroboration, editing.

\subsection{Missing Data}

Given that missing data in a longitudinal cohort may be related to clinical state, we explored further the $\mathrm{N}=530 \mathrm{missing}$-data cases. Cluster analysis grouped them into four 
cluster trends - each based on when data became missing in the seven years of the study. As shown in Table 2, the baseline depression and physical health scores for the study sample ( $\mathrm{N}=259)$ are roughly similar to the four missing data clusters, suggesting that those who left the study did not vary significantly in their depression or physical health. Still, differences across time could have existed. Nonetheless, it seems the exploratory results of the current study, at least at baseline, are reasonably valid with respect to the diamond cohort.

\section{< INSERT TABLE 2 ABOUT HERE >}

\section{5 Measures}

In terms of measures, we examined a rather exhaustive list of 40 variables used in [23]'s study of the diamond database. For more on the study design they used see also $[36,37,38]$.

\subsubsection{Global Outcome Variables}

Because our study was designed to explore and catalogue the different trajectories of comorbid depressive symptoms and physical health, we chose the following two wellknown global outcome variables. For depressive symptoms we used the Primary Care Evaluation of Mental Disorders Patient Health Questionnaire (PHQ-9) [40]. The PHQ-9 is a global, multipurpose instrument for screening, diagnosing and clinically measuring depression severity. The more severe the depression is, the higher the score. For physical health we used the physical health component (PCS-12) of the SF-12 Heath Survey [41]. The PCS-12 is a six-item, multi-purpose global assessment of physical health. The higher the score the better the physical health. With these two global outcomes variables identified, we could then model and explore their intersection across time and then group them into a working catalogue of their respective major and minor 
trends. A final note: once the final database was set, all scores on PHQ9 and PCS-12 were converted to z-scores to remove scale bias.

\subsubsection{Clinical Profile Variables}

Given that our second goal was to explore the set of clinical and socio-demographic factors accounted for the differences in the major and minor trends identified in the first part of our study, we examined 38 baselines variables from the diamond database, which were broken down into 16 socio-demographic factors, 18 psychological factors and 4 physical factors [23]. See tables 3 and 4 for details.

\subsection{Case-Based Computational Modeling}

For this study we employed a combination of statistical and computational techniques under the general methodology of case-based complexity [26,27,42]. Case-based complexity seeks to advance current statistical and computational methods by studying cases in complex systems terms [23,26,27]. Presently, a variety of techniques exist. The particular platform we used was the case-based computational modeling framework (CBCM) known as the SACS Toolkit [23,31]. For more on this approach, see 1.1 above.

\subsubsection{Analytic Procedure}

Our order of analysis is as follows. First, to identify and catalogue our major and minor comorbid trends, we followed current convention, employing a combination of (a) kmeans cluster analysis, (b) a self-organizing topographical neural net (SOM), and (c) expert knowledge. Next, to determine how the 38 clinical and socio-demographical variables combined to uniquely account for different comorbid trends, we used a

combination of ANOVA (for our continuous measures) and Chi-Square (for our discrete nominal measures) - see Table 3 and Table 4. This multi-step approach, which the 
SACS Toolkit employs, has proven highly useful, as it follows a rather rigorous process for corroboration $[23,43]$. Steps are as follows:

- Step 1: Creating longitudinal clusters. Modeling multiple comorbid trends involves clustering case trajectories. To do so, we treat each time instance as a measure, and the total of time instances/measures as the longitudinal k-dimensional vector profile for each case. The result is a database where the rows on the right-hand side of the database are cases (i.e., c1, c2, c3, .. n); and the columns across the top, in turn, are the discrete scores on depression and then physical health, at each time $(\mathrm{t})$ instance (i.e., $\mathrm{t} 1, \mathrm{t} 2, \mathrm{t} 3$... n) for each case - for details on this approach, see [23]. In turn, these trajectories are combined (appended to one another) so that the cluster solution is based on similarities in evolution across our two global outcomes measures. For the current study we appended the seven-year trajectories for PHQ9 and PCS-12 to each other for each of our $\mathrm{N}=259$ cases.

- Step 2: K-means. Analysis begins with k-means, which requires researchers to postulate the expected number of cluster trends, based on current theory. For the current study, given our literature review, we assumed there would be several large and mostly healthy cluster trends, followed by a handful of smaller and more pathological trends, ending with a group of high dynamic, minor cluster trends with high rates of comorbid depression and physical unhealthiness. As discussed in the results, k-means arrived at an 18-cluster solution.

- Step 3: SOM. The next step is to corroborate the k-means 18-cluster solution using the self-organizing topographical neural net (SOM). The current study used the SOM Toolkit [44]. Because the SOM engages in unsupervised cluster analysis, it decides which cluster solution is optimal - based on two validity measures: quantization error and topographical error $[45,46]$. While these error measures are unstandardized, the closer to zero the better; with topographical error scores less than 10 considered a 
good fit. Similar to Google Analytics, if the unsupervised SOM is a good fit and arrives at a solution similar to the k-means it provides effective corroboration.

- Step 4: Visual Inspection of SOM. As shown in Figure 1, the SOM graphs its cluster solution onto a multi-dimensional surface called the u-matrix. On the u-matrix, comorbid depressive symptoms and physical health cases most like one another are graphically positioned as nearby neighbors, with the most unlike cases placed furthest apart. As shown later in Figure 1 (Map A top and side view), the u-matrix is also topographical: valleys (darker colored) areas represent comorbid cluster trends that are more similar; while hilly, brighter colored areas show comorbid cluster trends that are more distinct.

- Step 5: Comparing k-means to SOM. Map B is a two-dimensional version of Map A, which allows for visual inspection of how the SOM clustered the $\mathrm{N}=259$ cases for the current study. Cases on this version of the u-matrix (as well as Map A) were labeled according to their k-means cluster membership (the 18-cluster solution) to see if the SOM arrived at a similar solution, which it did.

- Step 6: Expert Corroboration: With the k-means and SOM corroborated, an expert panel is assembled to review the results. To facilitate this process, a visualization of the comorbid depressive symptoms and physical health trends was also created, as shown in Figure 2. This allowed the panel to visually inspect the trends and name and catalogue their differences, as well as get rid of or collapse trends into one another. For the current study, our panel of primary care physicians and mental health professionals (which included three of the current authors for this study) collapsed several of the small-n, high dynamic, minor trends together, resulting in the final exploratory 11-cluster solution shown in figures 1 and 2.

The names of these clusters, in order, were: Healthy $(n=58)$, Okay Vacillate $(n=20)$, Okay Same $(n=27)$, Okay Improving $(n=26)$, Moderate Depression Improving $(\mathrm{n}=18)$, Episodic Depression $1(\mathrm{n}=16)$, Episodic Depression $2(\mathrm{n}=22)$, Moderate 
Depression Poor Health $(\mathrm{n}=14)$, Unhealthy $(\mathrm{n}=9)$, Chronic Ill $(\mathrm{n}=23)$ and a collection of small- $n$ trends grouped together to form the Oscillators cluster $(n=17)$. Still, our expert panel did agree that, despite the important insights they provide on highdynamic depression, the Unhealthy and Oscillating clusters, given their small-n size, could be a statistical artifact of using k-means cluster analysis and unsupervised artificial intelligence to arrive at them.

- Step 7: Etiology of comorbid trajectories. To determine how the various combinations of our 38 clinical and socio-demographic variables accounted for our eleven trends, a combination of ANOVA and Chi-Square was used. However, given the database is only $\mathrm{N}=259$, we did not engage in any post-hoc t-tests; as the chance for error with an 11-cluster solution across 38 variables, even with the most conservative of statistics, would be too high.

- Step 8: Modeling collective large-scale dynamics. To model the global temporal dynamics of the vector field, CBDM creates what it calls the microscopic model. For the purposes of normalization, all data for the microscopic model were converted to Z-scores. We used differential equations and smooth curve fitting techniques to compute the velocities for PHQ9 and PCS12; followed by using a genetic algorithm to fit a polynomial differential equation to the velocities - see Figure 3. The microscopic model (vector field, $\boldsymbol{V}$ ) uses the eighteen trajectories upon which the eleven trends are based to construct a state-space of all possible trajectories, for all seven years of the study, starting with the baseline $(t=0)$. The form of $\boldsymbol{V}$, which is a part of the ODE, is not known to us ahead of time, as our goal is to fit curves to data, rather than the GMM approach, which fits data to curves. This is key to the novelty of our approach. To run our genetic algorithm, we used Eureqa's software [47]. The component functions of the vector field are constrained to have a polynomial form. We choose a polynomial fit without any constraint on the degree, and use the mean squared error with the Akaike information criterion as an error measure. The software 
provides a measure of stability and maturity: 'stability' refers proportionally to how long ago the top solutions were modified among the multiple solutions provided; 'maturity' refers to how long ago any of the solutions have improved. Stability and maturity values close to $100 \%$ suggest the solutions cannot be improved. The software shows multiple solutions ordered according to their level of complexity of polynomials and fit. The mid-range solutions are, generally speaking, the best.

- Step 9: Constructing comorbid trend narratives. The last step was to use our expert panel to construct a clinical narrative for each of the eleven trends.

\section{RESULTS}

\subsection{Cluster Trends}

As outlined in Step 6 of the procedures section of the Methods, including the names for each trend, the current study identified eleven major and minor comorbid trends across the eleven time stamps explored (baseline; three, six and nine months; and then years 1 through 7). As a reminder from Section 2.6.1, this solution was an expert-based reduction of the original 18 clusters identified by k-means; also, some of the smaller trends, such as Unhealthy and Oscillators, given their small-n size, could be, in part, a statistical artifact of the analyses. Still, the validity estimate for our exploratory SOM solution was satisfactory: quantization error $=2.56$; topographical error $=.02[45,46]-$ see Methods for interpreting these statistics.

Figure 1: Self-Organizing Topographical Map of 11 Major and Minor Trends < INSERT FIGURE 1 ABOUT HERE >

The eleven trends and their respective groupings are found in Figure 1. (See Methods for review on how to read Figure 1.) Looking at Map B, the SOM placed the Healthy trend $(\mathrm{N}=58)$ on the opposite side of the map from the Unhealthy $(\mathrm{N}=9)$, Moderate Depression 
Poor Health $(\mathrm{N}=14)$ and the Oscillators $(\mathrm{N}=17)$. In map A the Unhealthy $(\mathrm{N}=9)$ and some of the Oscillators are on a ridge in the upper right, separated from the rest of the cluster trends, suggesting that these cluster trends differ significantly from the rest. Map B also suggests that Okay Vacillating $(\mathrm{N}=20)$, Okay Improving $(\mathrm{N}=26)$ and Okay Same $(\mathrm{N}=27)$ are somewhat similar to the cases in the Healthy trend, as they are all in the valley of Map A, side-view. However, while Moderate Depression Improving $(\mathrm{N}=18)$ is also proximate to the Healthy trend, the topography of Map A (top and side view) suggests it is not as similar to Healthy as the other okay health trends as it is not as far down in the valley. It is also worth noting that the two episodic depression trends Episodic Depression $1(\mathrm{~N}=16)$ and Episodic Depression $2(\mathrm{~N}=22)$ - were placed near each other and in the middle. Finally, consistent with the k-means solution, Chronic Ill $(\mathrm{N}=23)$ is off to the left side, as a distinct cluster, separated by the green ridge shown in Map A, from the rest of the poor health trends.

Figure 2: Eleven Major and Minor Comorbid Depression/Physical Trends $<$ INSERT FIGURE 2 ABOUT HERE >

Figure 2 is a temporal visualization of Figure 1, showing how the eleven trends evolve across time. On the left side are the trends for depressive symptoms; and on the right side are their corresponding physical health trends. In terms of the y-axis for depressive symptoms, a high score indicates poor health; in contrast, a high score on physical wellbeing indicates excellent health. Also, as highlighted in gray on Figure 2, it is important to remember that there were a total of 4 time-stamps for the first year of the study (i.e., 0, 3, 6, 9, 12 months); as such, one would expect to see a higher degree of dynamics in these first several months - which we do see. 
Looking at Figure 2, the first four trends are the Healthy to Okay Healthy clusters, which were the largest and most stable, comprising $51 \%$ of the total cases in the study. From there, however, the dynamics begin to intensify and diversify, starting with the Moderate Health clusters. Finally, there were the Overall Poor Health clusters. In addition to making up the minor trends in the study, these clusters had a high degree of dynamic fluctuation. The only exception was Chronic Ill ( $\mathrm{N}=23$; Cluster 6), for which depressive symptoms were not dynamic or comorbid with poor physical health.

\section{< INSERT TABLES 3 AND 4 ABOUT HERE >}

\subsection{Etiological Profiles}

Table 3 and Table 4 provide the socio-demographic and clinical profile for each of the eleven trends in our study. Here we provide a narrative for these indicators. Still, given the richness and complexity of these different profiles, others may identify narratives different from the ones we found. Also, our exploratory goal here is to provide a quick sense of the clusters; knowing that exact etiological algorithms (rule extraction and the proper weighting of each factor's influence) can be developed through further replication and study.

Our first clinical narrative is for the healthiest cluster trend. Healthy $(N=58)$ : with high across-the-board rates of health and socio-demographic wellbeing, this trend is doing well. It is also the youngest.

Okay Vacillating $(N=20)$ : as the specific indicators in Table 3 and 4 show, this trend is struggling a bit, including declining physical health, but otherwise okay. Note: by 'okay' we mean that the scores on PHQ9 and PCS12 for this trend (as well as others below that use the same term) are in the satisfactory range, but are not exceptionally or especially 
good. This trend is also middle aged and, at baseline, $85 \%$ reported a chronic condition in last 12 months. Ten percent also report currently taking antipsychotics, the second highest rate among the trends; and $45 \%$ have a rural GP, the highest rate (along with the unhealthy group) among the trends.

Okay Same (N=27): Looking at the indicators in Table 3 and 4, this trend is doing 'okay' without any significant decline in psychological or physical health. At baseline, $74.1 \%$ reported a chronic condition in the last 12 months. This is one of the older groups. There is a significant abuse history, with $46.2 \%$ reporting childhood physical abuse, and $23.1 \%$ reporting severe childhood sexual abuse.

Okay Improving $(N=26)$ : this trend improves across time; and, overall, is younger and scoring well on social indicators. However, at baseline it has the highest rate of hazardous drinking (38.5\%) and one of the highest rates of substance abuse $(24 \%)$.

Moderate Depression Improving $(N=18)$ : struggles with moderate baseline depression that improves across time. However, this trend has the best physical health. Also, although over $80 \%$ are working, their social participation rates are among the lowest in the sample. The proportion reporting severe childhood sexual abuse is among the highest of the moderate heath trends, but severe childhood physical abuse is not.

Episodic Depression $1(N=16)$ and $2(N=22)$ : these two trends mirror each other, with each going up in depression as the other goes down, and with physical health on a somewhat dynamic but steady decline. There are, however, differences. Episodic Depression 1 is older, has lower scores for social support and participation, and only $43.8 \%$ are employed; it also has a higher rate of social support satisfaction. However, it is more likely to have experienced partner abuse and severe childhood physical abuse. 
Still, both trends have considerable and similar sexual abuse exposure. Episodic Depression 2, the younger of the two trends, has a higher probability of a chronic health problem and is less likely to have been told they have anxiety by a provider $(70.6 \%)$. But, this trend is more likely to use sedatives or antianxiety medication and there is a higher rate of drug dependence.

Moderate Depression Poor Health $(N=14)$ : older and not doing well socially or physically; however, this trend's depression trajectory improves across time, albeit dynamically. This trend also has the second highest annual visits to a health provider, and the second highest negative events score. Fifty percent are currently employed, with $21.4 \%$ reporting they cannot work. There are also drug dependence issues and some of the highest rates of childhood abuse. Finally, 92.9\% reported a chronic illness or disability at baseline and the second worst self-health rating of all the groups.

Unhealthy $(N=9)$ : this middle-aged trend has sustained poor physical and mental health. It also has, overall, the most disadvantaged socio-demographic profile. Psychological distress is also pronounced, with $100 \%$ being told by provider, at baseline, they have depression and anxiety. Childhood abuse exposure is second highest of all groups, and severe partner abuse is more than double the rate in any other group. In terms of physical health, they have the third highest rate of chronic illness; they have the worst self-health rating, and the highest rate of days missed for physical and emotional disorders.

Chronically Ill $(N=23)$ : this older trend is struggling with chronic illness, but only mild depression. However, in terms of physical illness, $73.9 \%$ reported a past chronic illness or disability; $73.9 \%$ reported a current chronic condition; $21.7 \%$ cannot work; and only $47.8 \%$ are currently employed. This trend also had the third worst self-health rating and the third highest number of days missed for a physical condition. 
Oscillators $(N=17)$ : As a reminder, our study did not seek to remove or ignore small-n trends in order to explore trajectories where the comorbid relationship between depression and physical health was high dynamic. Such was the case with the oscillator trend. Each of these eight minor trajectories - with the largest cluster added to this trend being $\mathrm{N}=4$ cases - fluctuates between moderate to severe levels of unhealthiness. As a group, the socioeconomic wellbeing of the Oscillators is average to below average. They also have (along with Okay Improving) the highest rates of substance abuse; very high rates of depression, anxiety and dysthymia; and the highest rate of antipsychotic medication usage. Abuse history is also significant, with $69.2 \%$ reporting childhood physical abuse and $46.2 \%$ reporting severe childhood sexual abuse. They also have one of the worst baseline self-health ratings, missing a significant number of days due to emotional or physical issues.

\subsection{Collective Large-Scale (Across Trend) Patterns}

To examine the collective large-scale dynamics of our eleven trends, we created the vector field in Figure 3, which is read as follows. Data were converted to z-scores, with coordinate $(0,0)$ as the average score for both depression (y-axis) and physical health (xaxis). The shaded box shows the standard deviations (s.d.) within which the eleven trends fell - which correspond, for comparison purposes, to the s.d. in Figure 2. In this shaded box are five pointers - poor health, moderate health, okay health, chronically ill and moderate depression improving - to help readers locate the particular state-space occupied by the eleven trends. The lines in Figure 3 illustrate the contours of comorbid depression and physical health, as they co-evolve across time/space. The arrows (some of which are highlighted in black) indicate the direction of the trajectories, as well as their velocity: the larger the arrow the faster the trajectory is moving at that point in time. As a final point, Figure 3 is not useful for exploring individual trajectories. Instead, it is to be 
examined for global dynamic trends - that is, large-scale collective patterns - that exist across all eleven trends in the study. In other words, it does not show the trajectory of a particular case, but the potential trajectories of all cases.

Figure 3: Microscopic Model of Global-Temporal Dynamics Across All Eleven Trends $<$ INSERT FIGURE 3 ABOUT HERE >

Looking at Figure 3, the vector field solution identified two unexpected global-temporal patterns, a spiraling source and a saddle-point, which evolve across time. In terms of a basic definition, spiraling sources and saddle-points identify critical attractor points in a system. If the trajectories around such a critical point repel and spiral away from it, it is called a spiraling source. If, however, trajectories follow conflicting courses of action, the critical point is called a saddle. As an example, consider the saddle for time $=84$ months. On all four sides the trajectories are converging; however, they never actually run into each other; instead, the saddle point repels them, forcing them back outward in different destinations. This is why it is called a saddle-point: it roughly approximates the critical point at which the different trajectories stop increasing or decreasing in timespace. In other words, a saddle point functions like a local minima/maxima, constituting a barrier for how low or high a trajectory can go. In contrast, the spiraling source serves a different function. As its name implies, it is a continuously and gradually widening curve, which winds itself away from a critical point in time/space. Trajectories are repelled away from (or drawn into) a spiraling source, increasing or decreasing the velocity of the trajectories as they reach the outer or inner rings of the curve.

\section{DISCUSSION}

While descriptive and inferential in nature, the purpose of this study was exploratory (as opposed to confirmatory): we sought to advance the study of the clinical complexities of 
comorbid depression and physical health by: (a) creating a catalogue of their multiple comorbid trajectories, particularly for primary care; (b) looking for any noteworthy largescale collective dynamics; and, in turn, (c) exploring the complex etiologies that accounted for these results. In other words, we were trying to see if we could use complete data at all time points to model dynamics (and their complex etiology) otherwise outside the conventional purview - as opposed to generalizing some set of confirmatory findings to the general primary care population. In turn, to create this tentative catalogue, we sought to overcome current methodological convention by employing case-based complexity, specifically the SACS Toolkit, which was created for modeling such complex health issues [23].

\subsection{Cluster Trends}

In terms of the utility of a complexity theory approach, our exploratory analysis concluded that the longitudinal evolution of comorbid depressive symptoms and physical health follows multiple major and minor trends, demonstrating that the more severe the depression, the more dynamic the trends. Most trends are somewhat similar to their neighboring trends. The exceptions are the Oscillators and Unhealthy groups, which varied in dynamic between each other and are very different from other groups, but depression and physical health are co-morbid; and the Chronically Ill, where physical health is often low dynamic and it is not necessarily comorbid with depression. What is also striking about the cluster solution is how stable most of the trends are, apart from the oscillators, which constitute a very small part of the total dataset. We do not know, however, whether depression symptoms would show a less stable pattern if the cohort participants had not received any treatment over the seven years, given that we did not explore this issue. Also, we do not know if the missing cases not explored might have demonstrated a different set of dynamics. 


\subsection{Clinical Profiles}

Looking across all eleven trends, we find that, similar to studies such as [24], sexual abuse, childhood physical abuse, partner violence, and negative life events generally increase except for the chronic illness group. These well-known socio-demographic determinants of mental health seem to be key in determining trend membership.

Another significant finding is the distinctness of the chronic illness trend. Cases in this trend seem to have physical illness that limits their function but they cope without necessarily getting depressed - beyond, perhaps, the transient low mood picked up on screening at baseline that resulted in them joining the cohort. This finding seems consistent with other research $[20,48,49,50]$. Also striking, this trend had low levels of sexual abuse and partner violence compared to the Unhealthy and Oscillators trends.

\subsection{Collective Large-Scale Dynamics}

The clinical utility of the vector field is that it brings alive the reality of the evolution of depression and physical health, by depicting it dynamically at a large-scale and across trends. Looking at the results, this stage of the analysis suggests that depression is more dynamic than typically portrayed by growth mixture modeling, and that some of the cases spiral in and out of depression, across time, regardless of their particular level of severity of depression, although the speed of change is slow towards the centre of the spiraling source. The identification of saddle points also suggests that there may be limits to what treatment can achieve for some people - particularly amongst the Unhealthy and Oscillator trends. However, it also suggests that saddle points are dynamic, so health care experts and public institutions (potentially through effective preventive policy) can potentially change them by, for example, reducing the physical and sexual abuse people (particularly women) experience. Again, these insights are exploratory and, therefore, further analysis and replication is necessary. 


\subsection{Implications for Interdisciplinary Clinical Practice}

The concern in the current literature (as outlined in the introduction) that health providers are missing the multiple trends of co-morbid depressive symptoms (including major depression) when treating people for their physical health seems to be well supported by the current study - and not just because depression is always comorbid with physical health; but because in some instances, as in the case of chronic illness, it is necessary to know when depression is neither significant or at a clinical level. There are also sociodemographic moderators predisposing many cases to the development of depression, particularly childhood abuse and partner abuse, to which clinicians need to give their attention. There are also, however, trajectories of depression/chronic illness that suggest that resilience can act as a barrier to the extremes of severe chronic illness/abuse. Conversely, the trajectories in the extremes of severe chronic illness/abuse tend not to lead back to improved physical and mental health; in other words, some cases, as found in the Unhealthy and Oscillator trends, remain ill without much chance of improvement which, again, suggests different forms of treatment.

Given these results, it is likely that the different major and minor trends where depression and physical health do co-evolve (and where we are too late to prevent causative factors such as childhood abuse) may benefit from different inter-disciplinary, team-based approaches or combinations of approaches to treatment. Clinical examples include tackling hazardous drinking, providing medication to lift mood during a dip, strengthening strategies for resilience, and improving the management of the physical condition or providing social support. 


\section{ACKNOWLEDGEMENTS AND DATA AVAILABILITY}

The data used were part of the diamond project, which is funded by the National Health and Medical Research Council (ID: 299869, 454463, 566511, 1002908). We acknowledge the 30 dedicated GPs, their patients, and practice staff for making the diamond study possible. We also acknowledge the institutional support of the University of Melbourne (AUS), University of Warwick (UK), and Kent State University (USA). Due to the clinical sensitivity of these data, they are not available to the public.

\section{FUNDING}

This study is funded by a grant from the National Health and Medical Research Council (NHMRC) (ID: 1059863). The funding source had no role in the design of this study and will not have any role during its execution, analyses, interpretation of the data, or decision to submit results.

\section{CONFLICTS OF INTREST}

None

\section{CONTRIBUTORS}

All four authors were involved in conceptualizing the manuscript, conducting the analyses, interpreting the results, outlining the references, and writing the paper and consent to its publication. 


\section{REFERENCES}

1. Gunn J, Diggens J, Hegarty K, Blashki G. A systematic review of complex system interventions designed to increase recovery from depression in primary care. BMC health serv research. 2006; 6: 88.

2. Gunn JM, Ayton DR, Densley K, et al. The association between chronic illness, multimorbidity and depressive symptoms in an Australian primary care cohort. Soc psychiatry \& psychiatric epidem. 2012; 47, 175-184.

3. Katon W, Lin EH, Kroenke K. The association of depression and anxiety with medical symptom burden in patients with chronic medical illness. Gen hosp psych. 2007; 29:147155.

4. Knowles SE, Chew-Graham C, Coupe N, et al. Better together? A naturalistic qualitative study of inter-professional working in collaborative care for co-morbid depression and physical health problems. Implementation Sci. 2013; 8:110.

5. Menear M, Duhoux A, Roberge P, Fournier L. Primary care practice characteristics associated with the quality of care received by patients with depression and comorbid chronic conditions. Gen hosp psych. 2014; 36:302-309.

6. O'Dowd T. Depression and multimorbidity in psychiatry and primary care. J clinical psych. 2014; 75:1319-1320. 
7. Smith DJ, McLean G, Martin D, et al. Depression and multimorbidity: a crosssectional study of 1,751,841 patients in primary care. J clinical psych. 2014; 75:1202-8.

8. Moussavi S, Chatterji S, Verdes E, Tandon A, Patel V, Ustun B. Depression, chronic diseases, and decrements in health: results from the World Health Surveys. Lancet. 2007; 370:851-858.

9. Hackett ML, Pickles K. Part I: frequency of depression after stroke: an updated systematic review and meta- analysis of observational studies. Int J Stroke. 2014; 9:1017-1025.

10. Lunnay B, Bywood P. Co-morbidity of mental and physical illness: Meeting unmet care needs. Primary Health Care Res \& Info Service. 2011; 18:1-2. https://core.ac.uk/download/pdf/14947510.pdf Accessed 20 August 2018.

11. Mathers C. The global burden of disease: 2004 update. World Health Organization. 2008. http://www.who.int/healthinfo/global_burden_disease/2004_report_update/en/ Accessed 20 August 2018.

12. Naylor C, Parsonage M, McDaid D, Knapp M, Fossey M, Galea A. Long-term conditions and mental health: the cost of co-morbidities. The King's Fund. 2012. https://www.kingsfund.org.uk/sites/default/files/field/field_publication_file/long-termconditions-mental-health-cost-comorbidities-naylor-feb12.pdf. Accessed 20 August 2018.

13. Thombs BD, Bass EB, Ford DE, et al. Prevalence of depression in survivors of acute myocardial infarction. J gen int med. 2006; 21:30-38.

14. Wallace R, Ackermann R, Basen-Engquist K, et al. Living well with chronic illness: $a$ call for public health action. Institute of Medicine of the National Academies. 2012. http://nationalacademies.org/hmd/Reports/2012/Living-Well-with-Chronic-Illness.aspx Accessed 20 August 2018.

15. Weiss SJ, Haber J, Horowitz JA, Stuart GW, Wolfe B. The inextricable nature of mental and physical health: Implications for integrative care. J Amer Psych Nurses Assoc. 2009; 15: 371-382. 
16. Ram N, Grimm KJ. Methods and measures: Growth mixture modeling: A method for identifying differences in longitudinal change among unobserved groups. Int $j$ behave development. 2009; 33: 565-576.

17. Cramer AO, van Borkulo CD, Giltay EJ. Major depression as a complex dynamic system. PloS one. 2016; 11: p.e 0167490.

18. Pilling S, Anderson I, Goldberg, D Meader, Taylor C. Depression in adults, including those with a chronic physical health problem: summary of NICE guidance. BMJ. 2009; 339(10.1136).

19. Kang HJ, Kim SY, Bae KY, et al. Comorbidity of depression with physical disorders: research and clinical implications. Chonnam medical journal. 2015; 51: 8-18.

20. Menear M, Doré I, Cloutier AM, et al. The influence of comorbid chronic physical conditions on depression recognition in primary care: a systematic review. $J$ psychosomatic res. 2015; 78: 304-313.

21. Egede LE. Major depression in individuals with chronic medical disorders: prevalence, correlates and association with health resource utilization, lost productivity and functional disability. Gen hosp psych. 2007; 29: 409-416.

22. Ng CG, Boks MP, Zainal NZ, de Wit NJ. The prevalence and pharmacotherapy of depression in cancer patients. J affec dis. 2011; 131: 1-7.

23. Castellani B, Rajaram R, Gunn J, Griffiths F. Cases, clusters, densities: Modeling the nonlinear dynamics of complex health trajectories. Complexity. 2016; 21: 160-180.

24. Gunn J, Elliott P, Densley K, et al. A trajectory-based approach to understand the factors associated with persistent depressive symptoms in primary care. $J$ affect dis. 2013; 148: 338-346.

25. Henly SJ, Wyman JF, Findorff MJ. Health and illness over time: The trajectory perspective in nursing science. Nursing research. 2011; 60(3 Suppl): S5.

26. Byrne D, Callaghan G. Complexity theory and the social sciences: The state of the art. Routledge; 2013.

27. Byrne D, Ragin CC. The Sage handbook of case-based methods. Sage; 2009. 
28. Capra F, Luisi PL. The systems view of life: A unifying vision. Cambridge University Press; 2014.

29. Bar-Yam Y. Improving the effectiveness of health care and public health: a multiscale complex systems analysis. Am J Pub Health. 2006; 96(3): 459-466.

30. Mitchell M. Complexity: A guided tour. Oxford University Press; 2009.

31. Castellani B, Rajaram R. Case-based modeling and the SACS Toolkit: a mathematical outline. Computational \& Math Organization Theory. 2012; 18: 153-174.

32. Castellani B, Schimpf C, Hafferty F. Medical sociology and case-based complexity science: a user's guide. In: Handbook of Systems and Complexity in Health. Springer New York; 2013. Pp 521-535.

33. Castellani B, Rajaram R, Buckwalter JG, Ball M, Hafferty F. Place and health as complex systems: a case study and empirical test. Springerbriefs; 2015.

34. Rajaram R, Castellani B. The utility of nonequilibrium statistical mechanics, specifically transport theory, for modeling cohort data. Complexity. 2015; 20: 45-57.

35. Rajaram R, Castellani B. Modeling complex systems macroscopically: Case/agent based modeling, synergetics, and the continuity equation. Complexity. 2012: 8-17.

36. Boardman F, Griffiths F, Kokanovic R, Potiriadis M, Dowrick C, Gunn J. Resilience as a response to the stigma of depression: A mixed methods analysis. J affect dis. 2011; 135: $267-276$.

37. Gunn JM, Gilchrist GP, Chondros P, et al. Who is identified when screening for depression is undertaken in general practice? Baseline findings from the Diagnosis, Management and Outcomes of Depression in Primary Care (diamond) longitudinal study. Med J Australia. 2008; 188: 119.

38. Potiriadis M, Chondros P, Gilchrist G, Hegarty K, Blashki G, Gunn JM. How do Australian patients rate their general practitioner? A descriptive study using the General Practice Assessment Questionnaire. Med J Australia. 2008; 189:215-219.

39. Gilchrist G, Gunn J. Observational studies of depression in primary care: what do we know? BMC Family practice. 2007; 8(1): 28. 
40. Spitzer RL, Kroenke K, Williams JB, Patient Health Questionnaire Primary Care Study Group. Validation and utility of a self-report version of PRIME-MD: the PHQ primary care study. Jama. 1999; 282:1737-1744.

41. Ware JE, Kosinski M, Keller SD. A 12-Item Short-Form Health Survey: construction of scales and preliminary tests of reliability and validity. Med care. 1996; 34:220-233.

42. Case-Based Modeling and the SACS Toolkit Website. http://www.artsciencefactory.com/cases.html Accessed 20 August 2018.

43. Jain AK. Data clustering: 50 years beyond K-means. Pattern recognition letters. 2010; 31(8): 651-666.

44. Homepage of SOM Toolbox, a function package for Matlab 5 implementing the Self-Organizing Map (SOM) algorithm http://www.cis.hut.fi/somtoolbox/ Accessed 20 August 2018.

45. Kiviluoto K. Topology preservation in self-organizing maps. Proceeding Int Conf Neural Networks (ICNN). 1996; 294-299.

46. Vesanto J, Himberg J, Alhoniemi E, Parhankangas J. Self-organizing map in Matlab: the SOM Toolbox. Proceedings Matlab DSP conference. 1999; 99:16-17.

47. Eureqa ${ }^{\circledR}$ : The A.I.-Powered Modeling Engine https://www.nutonian.com/products/eureqa/ Accessed 20 August 2018.

48. Bonsaksen T, Fagermoen MS, Lerdal A. Trajectories of self-efficacy in persons with chronic illness: an explorative longitudinal study. Psych \& health. 2014; 29(3): 350-364.

49. Scott KM, Von Korff M, Alonso J, et al. Mental-physical co-morbidity and its relationship with disability: results from the World Mental Health Surveys. Psych med. 2009;39:33-43.

50. Scott KM, Bruffaerts R, Tsang A, et al. Depression-anxiety relationships with chronic physical conditions: results from the World Mental Health Surveys. J affect dis. 2007; 103:113-120.

51. Baum FE, Bush RA, Modra CC, et al. Epidemiology of participation: an Australian community study. J Epidemiol \& Com Hlth. 2000; 54:414-423. 
52. Hegarty K, Sheehan M, Schonfeld C. A multidimensional definition of partner abuse: development and preliminary validation of the Composite Abuse Scale. J fam violence. 1999;14:399-415.

53. MacMillan HL, Fleming JE, Trocmé N, et al. Prevalence of child physical and sexual abuse in the community: results from the Ontario Health Supplement. Jama. 1997;278:131-135.

54. Sarason, I.G., Sarason, B., Shearin, E., Pierce, G. A brief measure of social support: practical and theoretical implications. J Soc \& Personal Relationships. 1987;4:497.

55. World Health Organization. Composite International Diagnostic Interview (CIDIAuto), Version 2.1. World Health Organization, Geneva; 1997. 


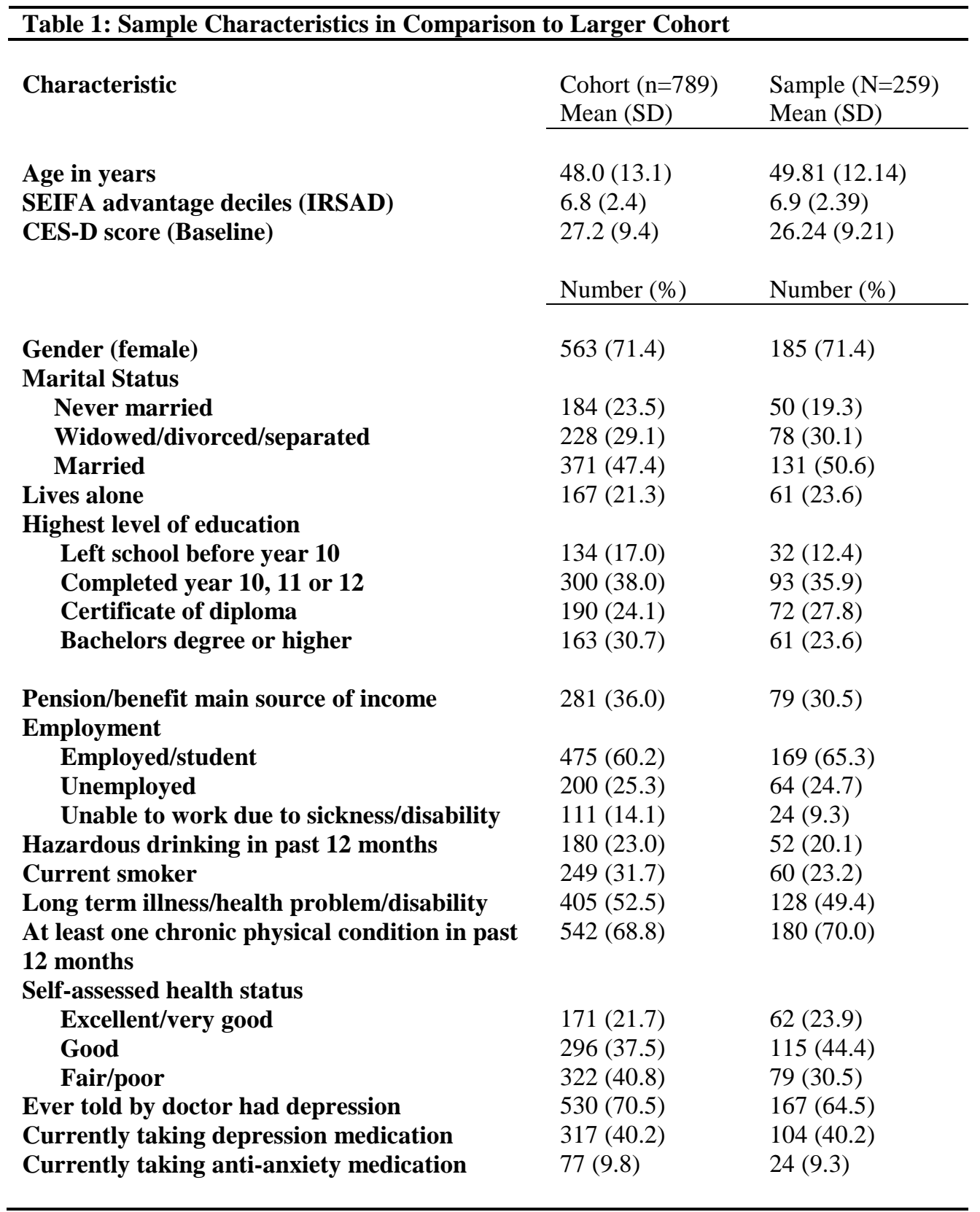




\begin{tabular}{lllll|l}
\hline Table 2: Cluster Analysis of N=530 Missing Data Cases & \multicolumn{1}{l}{} \\
\hline Cluster Name & $\begin{array}{l}\text { Missing data } \\
\text { from start of } \\
\text { study forward }\end{array}$ & $\begin{array}{l}\text { Missing data } \\
\text { from middle of } \\
\text { study forward }\end{array}$ & $\begin{array}{l}\text { Missing data } \\
\text { from end of } \\
\text { study forward }\end{array}$ & $\begin{array}{l}\text { Data missing } \\
\text { but no major } \\
\text { trend }\end{array}$ & $\begin{array}{l}\text { N=259 Valid } \\
\text { Cases in the } \\
\text { Study }\end{array}$ \\
\cline { 2 - 6 } & & $\mathrm{N}=84$ & $\mathrm{~N}=159$ & $\mathrm{~N}=173$ & $\mathrm{~N}=259$ \\
Count & $\mathrm{N}=114$ & 10.11 & 10.80 & 11.68 & 10.03 \\
PHQ9 mean & 10.39 & 81.03 & 78.94 & 78.21 & 82.20 \\
PCS-12 mean & 80.67 & & &
\end{tabular}


Longitudinal Trend

\begin{tabular}{|c|c|c|c|c|c|c|c|c|c|c|c|}
\hline & $\begin{array}{l}\text { Healthy } \\
(\mathrm{N}=58)\end{array}$ & $\begin{array}{l}\text { Okay } \\
\text { Vacillate } \\
(\mathrm{N}=20)\end{array}$ & $\begin{array}{l}\text { Okay } \\
\text { Same } \\
(\mathrm{N}=27)\end{array}$ & $\begin{array}{l}\text { Okay } \\
\text { Improving } \\
(\mathrm{N}=26)\end{array}$ & $\begin{array}{l}\text { Moderate } \\
\text { Depression } \\
\text { Improving } \\
(\mathrm{N}=18)\end{array}$ & $\begin{array}{l}\text { Episodic } \\
\text { Depression } 1 \\
(\mathrm{~N}=16)\end{array}$ & $\begin{array}{l}\text { Episodic } \\
\text { Depression } 2 \\
(\mathrm{~N}=22)\end{array}$ & $\begin{array}{l}\text { Moderate } \\
\text { Depression } \\
\text { Poor Health } \\
(\mathrm{N}=14) \\
\end{array}$ & $\begin{array}{l}\text { Unhealthy } \\
(\mathrm{N}=9)\end{array}$ & $\begin{array}{l}\text { Chronic } \\
\text { Ill } \\
(\mathrm{N}=23)\end{array}$ & $\begin{array}{l}\text { Oscillators } \\
(\mathrm{N}=17)\end{array}$ \\
\hline \multicolumn{12}{|l|}{ PSYCHOLOGICAL } \\
\hline$\overline{\text { Days out of role due to }}$ & $6.34^{\sim}$ & $8.7^{\sim}$ & $3.84^{\sim}$ & $4.38^{\sim}$ & $16.11^{\sim}$ & $7.81^{\sim}$ & $8.24^{\sim}$ & $19.64^{\sim}$ & $55.43^{\sim}$ & $10.22^{\sim}$ & $36.33^{\sim}$ \\
\hline emotional problems & $12.96 \mathrm{sd}$ & $15.39 \mathrm{sd}$ & $8.86 \mathrm{sd}$ & $12.14 \mathrm{sd}$ & $24.08 \mathrm{sd}$ & $13.83 \mathrm{sd}$ & $9.53 \mathrm{sd}$ & $29.10 \mathrm{sd}$ & $37.80 \mathrm{sd}$ & $22.15 \mathrm{sd}$ & $32.59 \mathrm{sd}$ \\
\hline Hazardous drinking & $20.7 \%+$ & $20.0 \%+$ & $11.5 \%+$ & $38.5 \%+$ & $5.6 \%+$ & $37.5 \%+$ & $19.0 \%+$ & $35.7 \%+$ & $22.2 \%+$ & $8.7 \%+$ & $11.5 \%+$ \\
\hline in last 12 months+ & $(0.1) \mathrm{se}$ & $(0.0) \mathrm{se}$ & $(-1.0) \mathrm{se}$ & $(2.1) \mathrm{se}$ & $(-1.4) \mathrm{se}$ & (1.5) se & $(-0.1) \mathrm{se}$ & (1.3) se & $(0.1) \mathrm{se}$ & $(-1.2) \mathrm{se}$ & $(-1.0) \mathrm{se}$ \\
\hline \multirow[t]{2}{*}{ Any substance abuse $a$} & $12.3 \%$ & $15.0 \%$ & $7.7 \%$ & $24.0 \%$ & $11.1 \%$ & $6.7 \%$ & $19.0 \%$ & $21.4 \%$ & $22.2 \%$ & $17.4 \%$ & $24.0 \%$ \\
\hline & $(-0.7) \mathrm{se}$ & $(-0.1) \mathrm{se}$ & $(-1.0) \mathrm{se}$ & $(1.0) \mathrm{se}$ & $(-0.5) \mathrm{se}$ & $(-0.9) \mathrm{se}$ & $(0.4) \mathrm{se}$ & $(0.5) \mathrm{se}$ & $(0.5) \mathrm{se}$ & $(0.2) \mathrm{se}$ & $(1.0) \mathrm{se}$ \\
\hline \multirow[t]{2}{*}{ Never smoked } & $46.6 \%$ & $40.0 \%$ & $51.9 \%$ & $42.3 \%$ & $47.1 \%$ & $43.8 \%$ & $54.5 \%$ & $42.9 \%$ & $44.4 \%$ & $43.5 \%$ & $38.5 \%$ \\
\hline & $(0.1) \mathrm{se}$ & $(-0.4) \mathrm{se}$ & $(0.5) \mathrm{se}$ & $(-0.2) \mathrm{se}$ & $(0.1) \mathrm{se}$ & $(-0.1)$ se & $(0.6) \mathrm{se}$ & $(-0.1)$ se & $(0.0) \mathrm{se}$ & $(-0.1)$ se & $(-0.5) \mathrm{se}$ \\
\hline \multirow[t]{2}{*}{ Currently smoke } & $22.4 \%$ & $15.0 \%$ & $11.1 \%$ & $15.4 \%$ & $29.4 \%$ & $25.0 \%$ & $22.7 \%$ & $35.7 \%$ & $44.4 \%$ & $13.0 \%$ & $42.3 \%$ \\
\hline & $(-0.1) \mathrm{se}$ & $(-0.8) \mathrm{se}$ & $(-1.3) \mathrm{se}$ & $(-0.8)$ se & $(0.5) \mathrm{se}$ & $(0.1) \mathrm{se}$ & $(-0.1) \mathrm{se}$ & (1.0) se & (1.3) se & $(-1.0) \mathrm{se}$ & $(2.0) \mathrm{se}$ \\
\hline Depression a current & $39.3 \% *$ & $25.0 \% *$ & $34.6 \% *$ & $42.3 \% *$ & $72.2 \% *$ & $66.7 \% *$ & $71.4 \% *$ & $78.6 \% *$ & $88.9 \% *$ & $47.8 \% *$ & $88.0 \% *$ \\
\hline problem* & $(-1.5) \mathrm{se}$ & $(-1.8) \mathrm{se}$ & $(-1.4) \mathrm{se}$ & $(-0.8)$ se & $(1.0) \mathrm{se}$ & $(0.7) \mathrm{se}$ & (1.1) se & (1.2) $\mathrm{se}$ & (1.4) se & $(-0.4) \mathrm{se}$ & (2.3) se \\
\hline Ever told by doctor & $50.9 \% *$ & $57.9 \% *$ & $50.0 \% *$ & $57.7 \% *$ & $70.6 \% *$ & $86.7 \% *$ & $85.7 \% *$ & $92.9 \% *$ & $100 \% *$ & $61.9 \% *$ & $88.0 \% *$ \\
\hline had depression* & $(-1.5) \mathrm{se}$ & $(-0.5) \mathrm{se}$ & $(-1.1) \mathrm{se}$ & $(-0.6) \mathrm{se}$ & $(0.2) \mathrm{se}$ & $(0.9) \mathrm{se}$ & $(1.0) \mathrm{se}$ & (1.2) $\mathrm{se}$ & (1.2) se & $(-0.3)$ se & (1.3) se \\
\hline Ever told by doctor & $41.8 \% *$ & $58.8 \% *$ & $30.4 \% *$ & $42.9 \% *$ & $62.5 \% *$ & $91.7 \% *$ & $70.6 \% *$ & $77.8 \% *$ & $100 \% *$ & $50.0 \% *$ & $73.9 \% *$ \\
\hline had anxiety* & $(-1.4) \mathrm{se}$ & $(0.2) \mathrm{se}$ & $(-1.6) \mathrm{se}$ & $(-0.8)$ se & $(0.3) \mathrm{se}$ & (1.7) se & $(0.8) \mathrm{se}$ & $(0.9) \mathrm{se}$ & (1.6) se & $(-0.3) \mathrm{se}$ & (1.2) $\mathrm{se}$ \\
\hline \multirow[t]{2}{*}{ Dysthymia $* b$} & $1.8 \% *$ & $5.0 \% *$ & $0.0 \% *$ & $8.0 \% *$ & $11.1 \% *$ & $6.7 \% *$ & $9.5 \% *$ & $14.3 \% *$ & $44.4 \% *$ & $21.7 \% *$ & $28.0 \% *$ \\
\hline & $(-2.1) \mathrm{se}$ & $(-0.8)$ se & $(-1.7) \mathrm{se}$ & $(-0.4)$ se & $(0.1) \mathrm{se}$ & $(-0.5) \mathrm{se}$ & $(-0.2) \mathrm{se}$ & $(0.4) \mathrm{se}$ & (3.1) se & (1.6) se & (2.7) se \\
\hline Currently taking & $24.6 \% *$ & $30.0 \% *$ & $26.9 \% *$ & $23.1 \% *$ & $33.3 \% *$ & $37.5 \% *$ & $50.0 \% *$ & $57.1 \% *$ & $55.6 \% *$ & $26.1 \% *$ & $73.1 \% *$ \\
\hline depression meds* & $(-1.5) \mathrm{se}$ & $(-0.5) \mathrm{se}$ & $(-0.8) \mathrm{se}$ & $(-1.1) \mathrm{se}$ & $(-0.2) \mathrm{se}$ & $(0.1) \mathrm{se}$ & $(1.0) \mathrm{se}$ & (1.3) se & $(0.9) \mathrm{se}$ & $(-0.8)$ se & (3.1) se \\
\hline \multirow{2}{*}{$\begin{array}{l}\text { Currently taking anti- } \\
\text { anxiety meds }\end{array}$} & $8.6 \%$ & $5.0 \%$ & $3.7 \%$ & $0.0 \%$ & $22.2 \%$ & $6.3 \%$ & $22.7 \%$ & $0.0 \%$ & $22.2 \%$ & $8.7 \%$ & $11.5 \%$ \\
\hline & $(-0.2) \mathrm{se}$ & $(-0.6) \mathrm{se}$ & $(-0.9) \mathrm{se}$ & $(-1.6) \mathrm{se}$ & (1.8) se & $(-0.4)$ se & (2.1) se & $(-1.1) \mathrm{se}$ & (1.3) se & $(-0.1)$ se & $(0.4) \mathrm{se}$ \\
\hline Currently taking & $1.7 \% *$ & $10.0 \% *$ & $0.0 \% *$ & $0.0 \% *$ & $0.0 \% *$ & $0.0 \% *$ & $0.0 \% *$ & $7.1 \% *$ & $0.0 \% *$ & $0.0 \% *$ & $15.4 \% *$ \\
\hline Antipsychotic meds* & $(-0.6)$ se & (1.8) se & $(-0.9) \mathrm{se}$ & $(-0.9)$ se & $(-0.7) \mathrm{se}$ & $(-0.7)$ se & $(-0.8)$ se & $(0.9) \mathrm{se}$ & $(-0.5) \mathrm{se}$ & $(-0.8) \mathrm{se}$ & (3.6) se \\
\hline Currently taking & $3.4 \% *$ & $5.0 \% *$ & $0.0 \% *$ & $3.8 \% *$ & $0.0 \% *$ & $6.3 \% *$ & $27.3 \% *$ & $0.0 \% *$ & $0.0 \% *$ & $0.0 \% *$ & $7.7 \% *$ \\
\hline Sedative meds* & $(-0.5) \mathrm{se}$ & $(0.0) \mathrm{se}$ & $(-1.2) \mathrm{se}$ & $(-0.3) \mathrm{se}$ & $(-1.0) \mathrm{se}$ & $(0.2) \mathrm{se}$ & (4.7) se & $(-0.8) \mathrm{se}$ & $(-0.7)$ se & $(-1.1) \mathrm{se}$ & $(0.6) \mathrm{se}$ \\
\hline \multirow{2}{*}{$\begin{array}{l}\text { Partner abuse, } \\
\text { severe* } c\end{array}$} & $1.8 \% *$ & $5.0 \% *$ & $4.2 \% *$ & $4.0 \% *$ & $11.8 \% *$ & $20.0 \% *$ & $9.1 \% *$ & $14.3 \% *$ & $44.4 \% *$ & $0.0 \% *$ & $16.7 \% *$ \\
\hline & $(-1.7) \mathrm{se}$ & $(-0.5) \mathrm{se}$ & $(-0.7) \mathrm{se}$ & $(-0.8)$ se & $(0.5) \mathrm{se}$ & (1.5) se & $(0.1) \mathrm{se}$ & $(0.7) \mathrm{se}$ & (3.7) se & $(-1.3) \mathrm{se}$ & (1.4) se \\
\hline \multirow{8}{*}{$\begin{array}{l}\text { Childhood sexual } \\
\text { abuse* } d \\
\text { Childhood sexual } \\
\text { abuse, severe* } d \\
\text { Childhood physical } \\
\text { abuse* } d \\
\text { Childhood physical } \\
\text { abuse, severe }+d\end{array}$} & $12.1 \% *$ & $20.0 \% *$ & $26.9 \% *$ & $23.1 \% *$ & $35.3 \% *$ & $31.3 \% *$ & $38.1 \% *$ & $42.9 \% *$ & $44.4 \% *$ & $9.1 \% *$ & $46.2 \% *$ \\
\hline & $(-2.1) \mathrm{se}$ & $(-0.5) \mathrm{se}$ & $(0.1) \mathrm{se}$ & $(-0.3) \mathrm{se}$ & $(0.7) \mathrm{se}$ & $(0.4)$ se & (1.1) se & (1.2) se & (1.1) se & $(-1.6) \mathrm{se}$ & $(2.0) \mathrm{se}$ \\
\hline & $12.1 \% *$ & $20.0 \% *$ & $23.1 \% *$ & $19.2 \% *$ & $35.3 \% *$ & $25.0 \% *$ & $28.6 \% *$ & $35.7 \% *$ & $44.4 \% *$ & $9.1 \% *$ & $46.2 \% *$ \\
\hline & $(-1.8) \mathrm{se}$ & $(-0.4) \mathrm{se}$ & $(-0.1) \mathrm{se}$ & $(-0.5) \mathrm{se}$ & $(1.0) \mathrm{se}$ & $(0.1) \mathrm{se}$ & $(0.4) \mathrm{se}$ & $(0.9) \mathrm{se}$ & (1.3) se & $(-1.4) \mathrm{se}$ & (2.3) se \\
\hline & $27.6 \% *$ & $35.0 \% *$ & $46.2 \% *$ & $50.0 \% *$ & $33.3 \% *$ & $56.3 \% *$ & $50.0 \% *$ & $64.3 \% *$ & $55.6 \% *$ & $36.4 \% *$ & $69.2 \% *$ \\
\hline & $(-1.9) \mathrm{se}$ & $(-0.6)$ se & $(0.1) \mathrm{se}$ & $(0.4) \mathrm{se}$ & $(-0.7) \mathrm{se}$ & $(0.7) \mathrm{se}$ & $(0.4) \mathrm{se}$ & (1.1) se & $(0.5) \mathrm{se}$ & $(-0.6)$ se & (1.9) se \\
\hline & $12.1 \% *$ & $30.0 \% *$ & $19.2 \% *$ & $30.8 \% *$ & $16.7 \% *$ & $37.5 \% *$ & $27.3 \% *$ & $46.2 \% *$ & $44.4 \% *$ & $31.8 \% *$ & $42.3 \% *$ \\
\hline & $(-2.2) \mathrm{se}$ & $(0.3) \mathrm{se}$ & $(-0.8) \mathrm{se}$ & $(0.4)$ se & $(-0.8)$ se & $(0.8)$ se & $(0.0)$ se & (1.3) se & $(1.0) \mathrm{se}$ & $(-0.4)$ se & $(1.5) \mathrm{se}$ \\
\hline \multicolumn{12}{|l|}{ PHYSICAL } \\
\hline \multirow{6}{*}{$\begin{array}{l}\text { Chronic illness or } \\
\text { disability* } \boldsymbol{e} \\
\text { Chronic condition last } \\
12 \text { months } f \\
\text { Self-health rating } \boldsymbol{h} \sim\end{array}$} & $12.1 \% *$ & $35.0 \% *$ & $63.0 \% *$ & $34.6 \% *$ & $27.8 \% *$ & $56.3 \% *$ & $63.6 \% *$ & $92.9 \% *$ & $88.9 \% *$ & $95.7 \% *$ & $70.8 \% *$ \\
\hline & $(-4.1) \mathrm{se}$ & $(-0.9)$ se & (1.0) se & $(-1.1) \mathrm{se}$ & $(-1.3) \mathrm{se}$ & $(0.4)$ se & (0.9) se & (2.3) se & (1.7) se & (3.1) se & (1.5) se \\
\hline & $58.6 \%$ & $85.0 \%$ & $74.1 \%$ & $73.1 \%$ & $55.6 \%$ & $75.0 \%$ & $81.8 \%$ & $78.6 \%$ & $66.7 \%$ & $73.9 \%$ & $76.9 \%$ \\
\hline & $(-1.1) \mathrm{se}$ & $(0.7) \mathrm{se}$ & $(0.2) \mathrm{se}$ & $(0.1) \mathrm{se}$ & $(-0.8) \mathrm{se}$ & $(0.2) \mathrm{se}$ & $(0.6) \mathrm{se}$ & $(0.3) \mathrm{se}$ & $(-0.2) \mathrm{se}$ & $(0.2) \mathrm{se}$ & $(0.4) \mathrm{se}$ \\
\hline & $2.54^{\sim}$ & $2.90^{\sim}$ & $3.35^{\sim}$ & $2.81^{\sim}$ & $2.83^{\sim}$ & $3.00^{\sim}$ & $3.32^{2}$ & $3.79^{\sim}$ & $3.89^{\sim}$ & $3.68^{\sim}$ & $3.54^{\sim}$ \\
\hline & $0.76 \mathrm{sd}$ & $0.64 \mathrm{sd}$ & $0.75 \mathrm{sd}$ & $0.80 \mathrm{sd}$ & $0.99 \mathrm{sd}$ & $0.63 \mathrm{sd}$ & $0.65 \mathrm{sd}$ & $0.70 \mathrm{sd}$ & $1.05 \mathrm{sd}$ & $0.84 \mathrm{sd}$ & $1.24 \mathrm{sd}$ \\
\hline \multirow{2}{*}{$\begin{array}{l}\text { Days out of role for } \\
\text { physical health }\end{array}$} & $2.95^{\sim}$ & $6.95^{\sim}$ & $18.96^{\sim}$ & $13.81^{\sim}$ & $3.06^{\sim}$ & $7.07^{\sim}$ & $3.10^{\sim}$ & $19.21^{\sim}$ & $45.71^{\sim}$ & $22.37^{\sim}$ & $22.65^{\sim}$ \\
\hline & $8.52 \mathrm{sd}$ & $16.54 \mathrm{sd}$ & $25.57 \mathrm{sd}$ & $26.63 \mathrm{sd}$ & $9.35 \mathrm{sd}$ & $12.84 \mathrm{sd}$ & $3.71 \mathrm{sd}$ & $28.27 \mathrm{sd}$ & $41.86 \mathrm{sd}$ & $28.55 \mathrm{sd}$ & $31.07 \mathrm{sd}$ \\
\hline
\end{tabular}
include mean and standard deviation (sd).

* = Chi Square significant at .05 or higher.

$+=$ Chi Square significant at $p \leq .08$

$\sim=$ ANOVA significant at .001 or higher.

$\boldsymbol{a}=$ Any substance abuse (CIDI 12-month disorders) including alcohol World Health Organization, 1997. 


\section{Understanding Comorbid Depression/Physical Health Trajectories}

$\boldsymbol{b}=$ Dysthymia (CIDI 12 month-disorder) World Health Organization, 1997.

$\boldsymbol{c}=$ Partner abuse (CAS) Hegarty et al., 1999 (Scale used by Gunn et al., 2013 was 0: no abuse, 1: Other abuse, 3: Severe abuse.

$\boldsymbol{d}=$ Childhood sexual and physical abuse, MacMillan et al., 1997.

$\boldsymbol{e}=$ Long term illness, health problem or disability.

$f=$ At least one chronic physical condition in past 12 months, including asthma, emphysema, arthritis, hypertension, back problems, chronic sinusitis, lipid disorder, cancer, stroke, dermatitis.

$\boldsymbol{h}=$ Self-Health Rating: 1=excellent health, 2=very good, 3=good, 4=fair, 5=poor health.

\section{TABLE 4: Eleven Clinical Profiles for Major and Minor Trends on Key Sociological Factors}

Longitudinal Trend

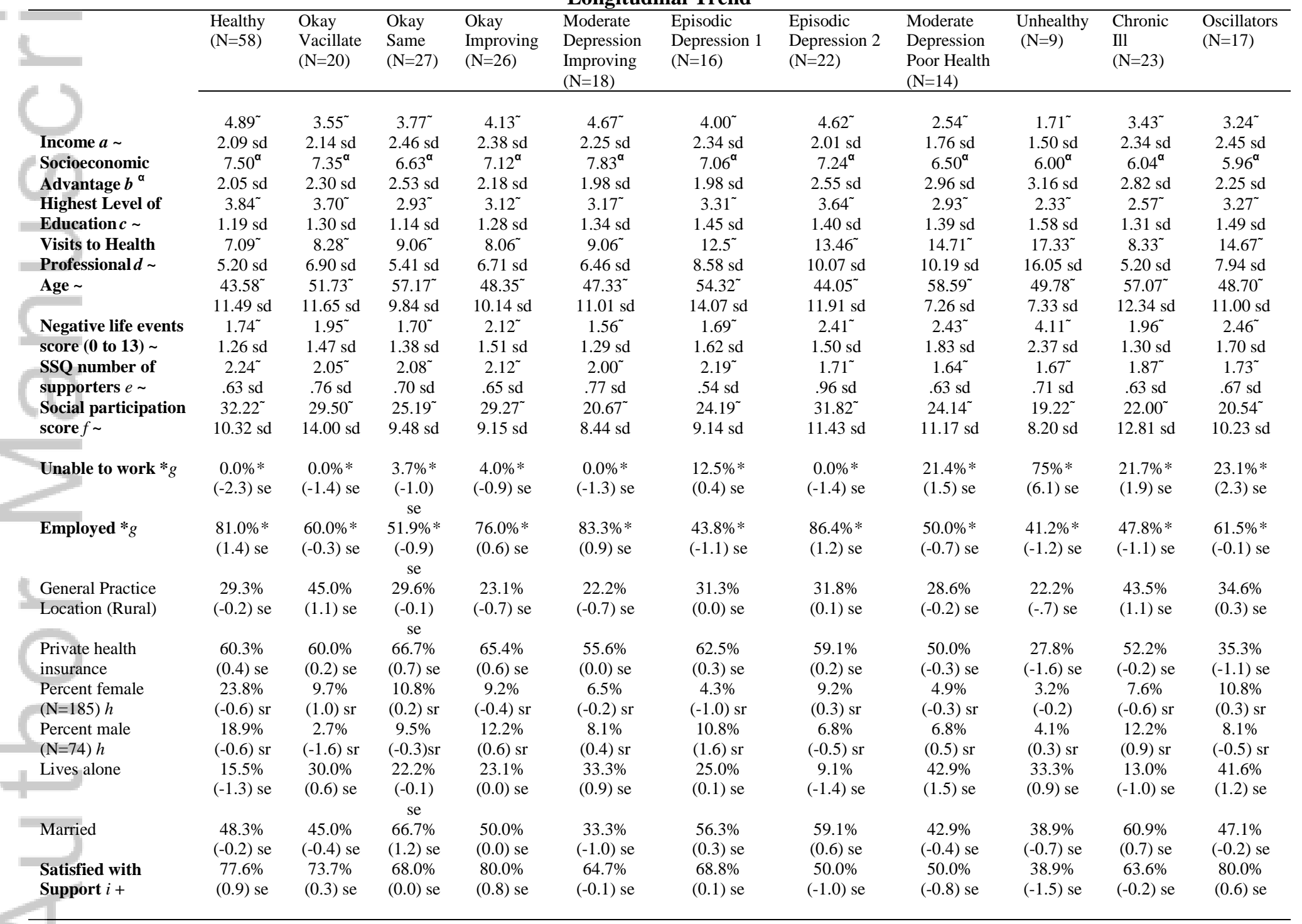

Bold Faced Factors had significant probability values. Chi Square includes percentage (\%) and standardized error (se) or standardized residual (sr); ANOVA 
include mean and standard deviation (sd).

* = Chi Square significant at .05 or higher.

$+=$ Chi Square significant at $\mathrm{p}=.06$.

$\sim$ = ANOVA significant at .05 or higher.

$\alpha=$ ANOVA significant at .08

${ }^{a}$ Income: $1=20,000$ or less; $7=70,000$ or higher (Australian currency).

${ }^{b}$ Socioeconomic Advantage: Index of relative socio-economic advantage and disadvantage (See Gunn et al., 2013 for more details.)

${ }^{c}$ Highest level of Education: 1=Left school before year 10; 2=Completed year 10; 3=Completed year 12; 4=Certificate/Diploma; 5=Bachelors or higher.

${ }^{d}$ Self reported visits to health professional includes number of visits to any and all health providers, from general practitioner to social worker.

${ }^{e}$ SSQ number of supporters (Sarason et al., 1987) mean out of 9.

${ }^{f}$ Social participation score (Baum et al., 2000) score range 0-90.

${ }^{g}$ For employment, we reported two different statistics $1=$ employed/student or $2=$ unable to work due to sickness or disability.

${ }^{h}$ This statistics provides the percentage of each gender for each cluster, relative to the total sample for each gender. Also, reported here is the chi-square standard residual, which is the difference between the observed count and the expected count and the standard deviation of the expected count.

${ }^{i}$ Satisfied with Support, 1=yes.

\section{FIGURE LEGENDS}

\section{Figure 1: Self-Organizing Topographical Map of 11 Major and Minor Trends}

Figure 1 reads as follows: U-Matrix and Components Maps for final eleven exploratory trends (co-morbid depression/physical health trajectories). NOTE: This solution was a reduction of the k-means 18-cluster solution -- which is why all three maps above show 18 different cluster numbers and their respective cluster name (which is one of the final eleven clusters). LEGEND: Map A and Map B are graphic representations of the cluster solution arrived at by the Self-Organizing Map (SOM) Neural Net, referred to as the UMatrix. In terms of the information they provide, Map A is a three-dimensional (topographical) u-matrix: for it, the SOM adds hexagons to the original map to allow for visual inspection of the degree of similarity amongst neighboring map units; the dark blue areas indicate neighborhoods of cases that are highly similar; in turn, bright yellow and red areas, as in the lower right corner of the map, indicate highly defined cluster boundaries. Map A Side View gives a more visually intuitive sense of the topography of the map. Map B is a two-dimensional version of Map A that allows for visual inspection of how the SOM clustered the individual cases. Cases on this version of the u-matrix (as well as Map A) were labeled according to their k-means cluster membership.

\section{Figure 2: Eleven Major and Minor Comorbid Depression/Physical Trends}

Figure 2 reads as follows: each graph provides the longitudinal cluster centroids for the eleven major and minor trends in the data. On the left side are the centroids for depression (our first trace variable); and on the right side are the centroids for physical health (our other trace variable). The $\mathrm{x}$-axis represents time, moving from time $=0$ to time $=84$ months. In terms of the $y$-axis for depression, a high score on PHQ-9 indicates poor health; in contrast, a high score on PCS-12 (physical health) indicates excellent 
health. The graphs also include labels for each region, going from 'severe' to 'mild' for depression; and 'poor health' to 'good health' for physical health. In terms of sample statistics, for PHQ-9, the mean was 7.93 (standard deviation =6.04); and for PCS-12, the mean was 45.16 (standard deviation $=11.58)$.

\section{Figure 3: Microscopic Model of Global-Temporal Dynamics Across Eleven Trends}

Figure 3 reads as follows: The microscopic model uses the non-clustered data to construct a state-space of all possible trajectories, for all seven years of the study, starting with the baseline (time $=0$ ) and proceeding, across the next eight snapshots, to the end (time $=84$ months). All possible trajectories are visualized in the form of arrows (shown in grey between the blue trend lines), which show direction and velocity; the larger the arrow the faster the trajectory. For the purposes of normalization, all data were converted to $\mathrm{z}$-scores; as such, coordinate $(0,0)$ is the center; with the majority of the data falling within two standard deviations (the inner grey area on each graph). NOTE1: The graphs were cropped at three standard deviations, in order to visualize more fully the globally dynamic behavior of the model; while none of the data actually fell outside the first two standard deviations. In other words, this model does not show the trajectories of specific cases and should not be read as such. Instead, it ia read as a map of all possible trajectories, with the focus on identifying (as the results section does) major global dynamics. NOTE2: The $\mathrm{x}$-axis is physical health (with poor physical health on the left and good physical health on the right); the y-axis is depression, going from low to high levels of depression as one moves upward along the axis. NOTE3: Two key globaldynamic behaviors were identified: a saddle point and a spiraling source. The graph for time $=0$ was likewise labeled to give the reader a rough sense of the different quadrants, from high physical health and low depression to low physical health and high depression. 


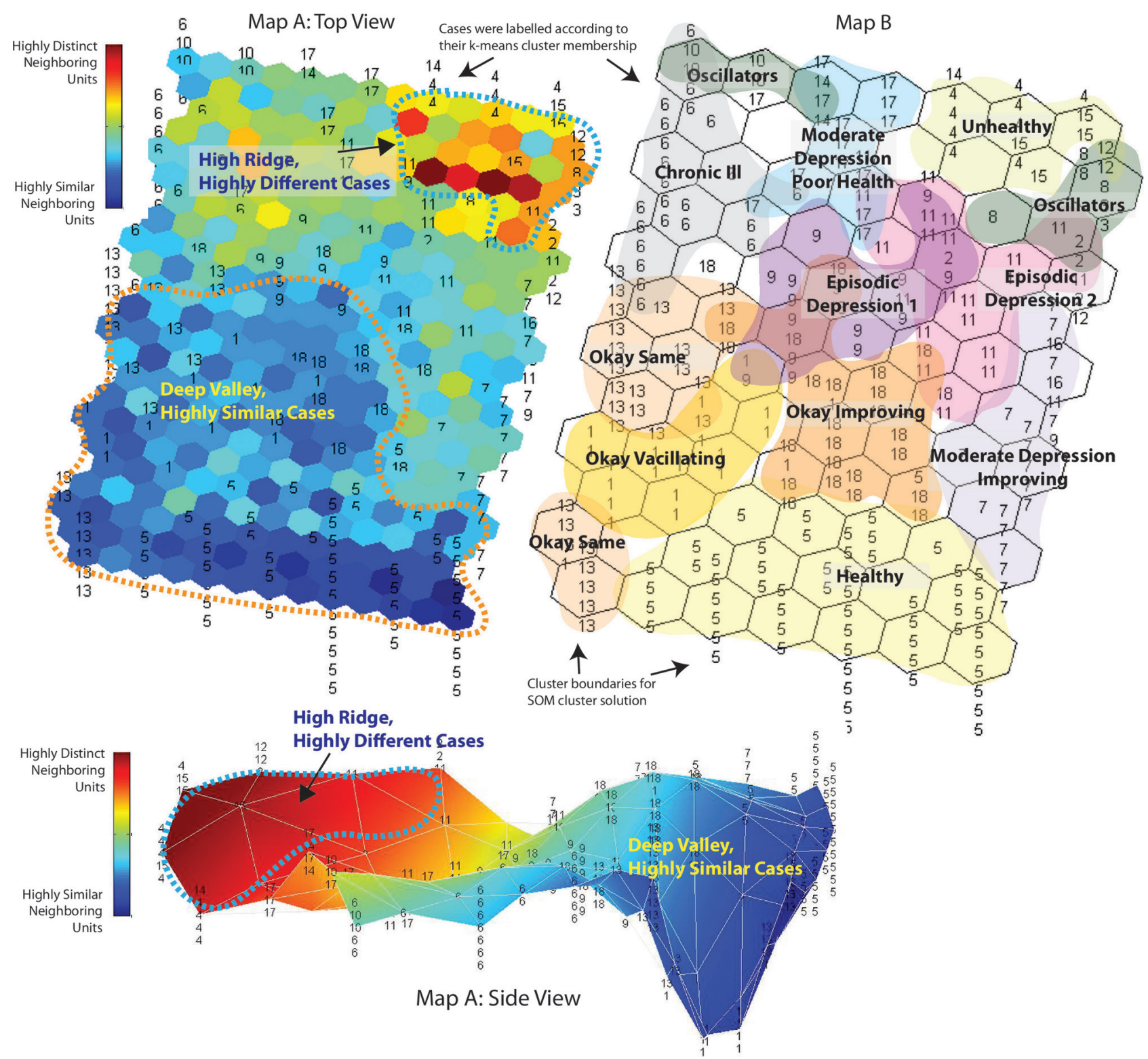

jep_13042_f1.eps 
Healthy to Okay Health Group
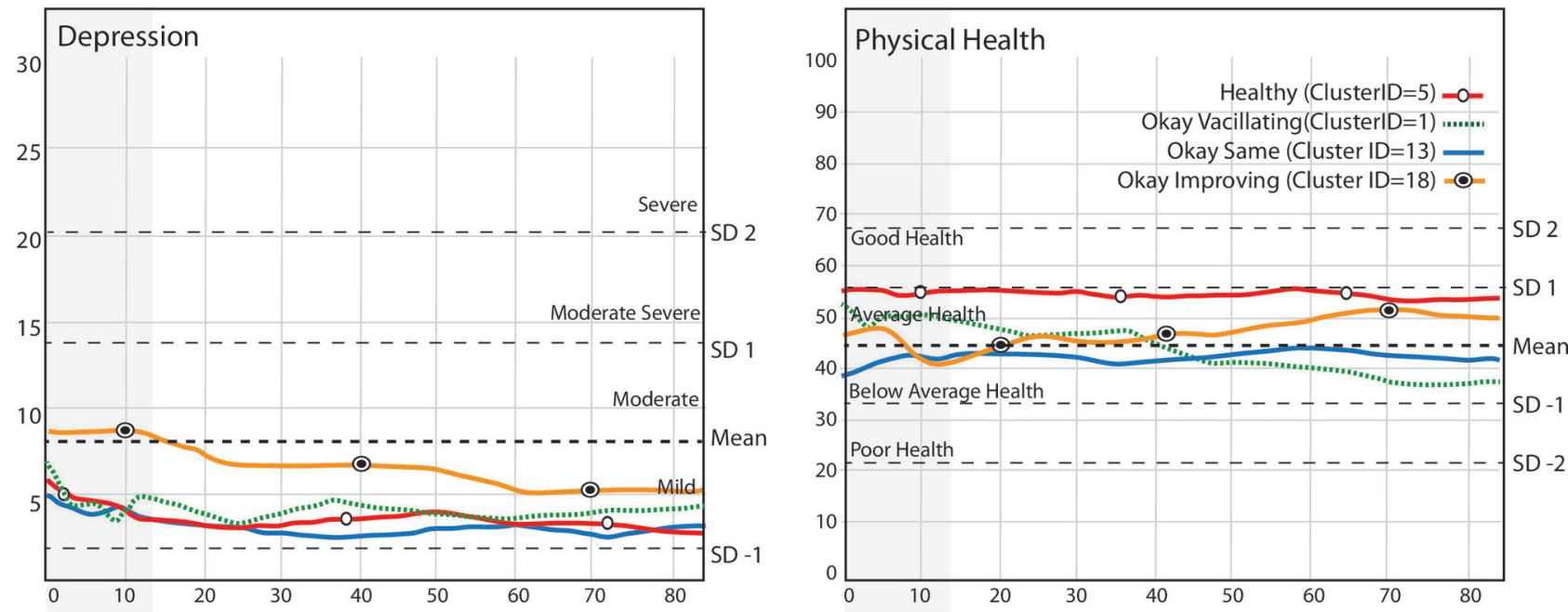

Moderate Health Group
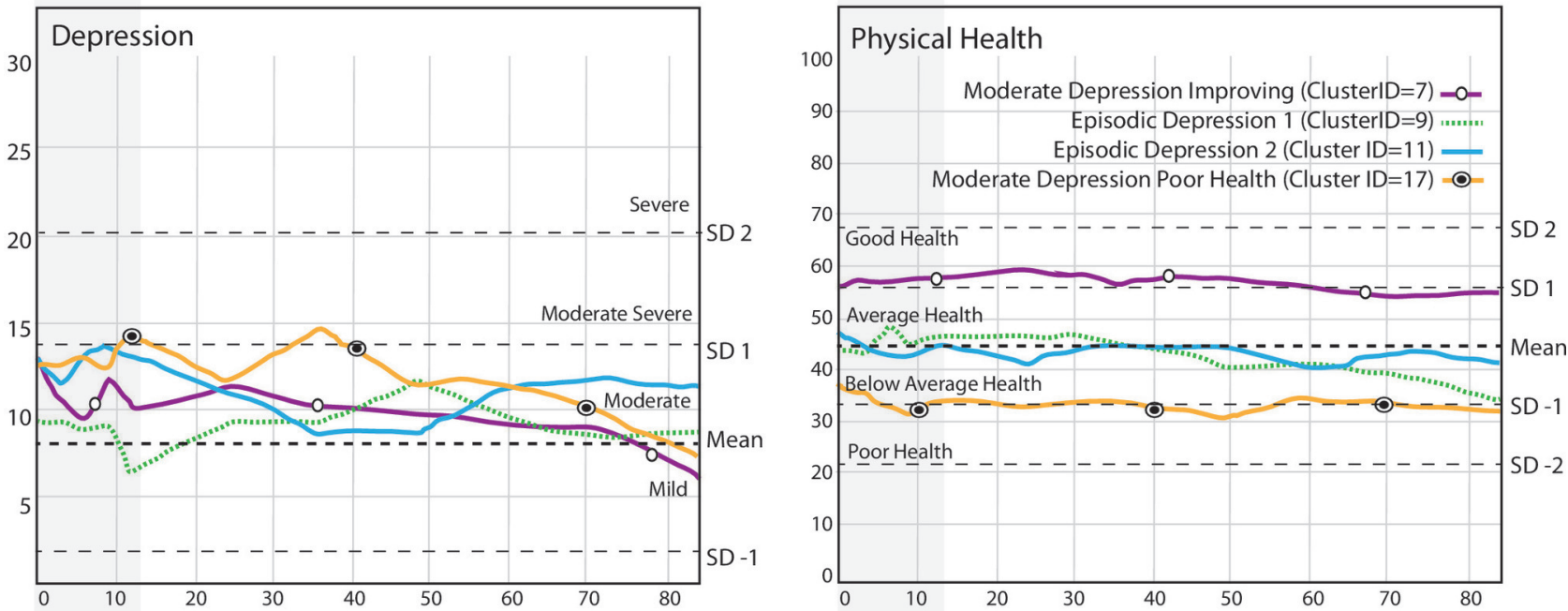

Overall Poor Health Group
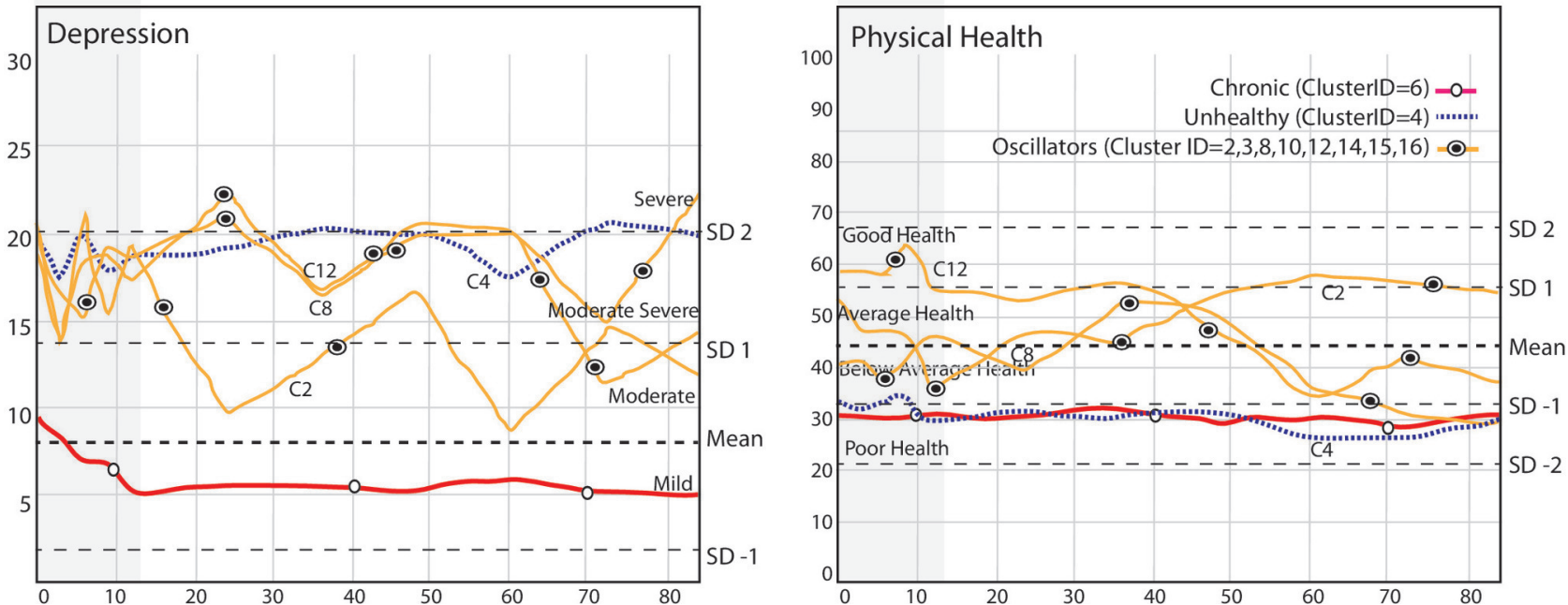

jep_13042_f2.eps 

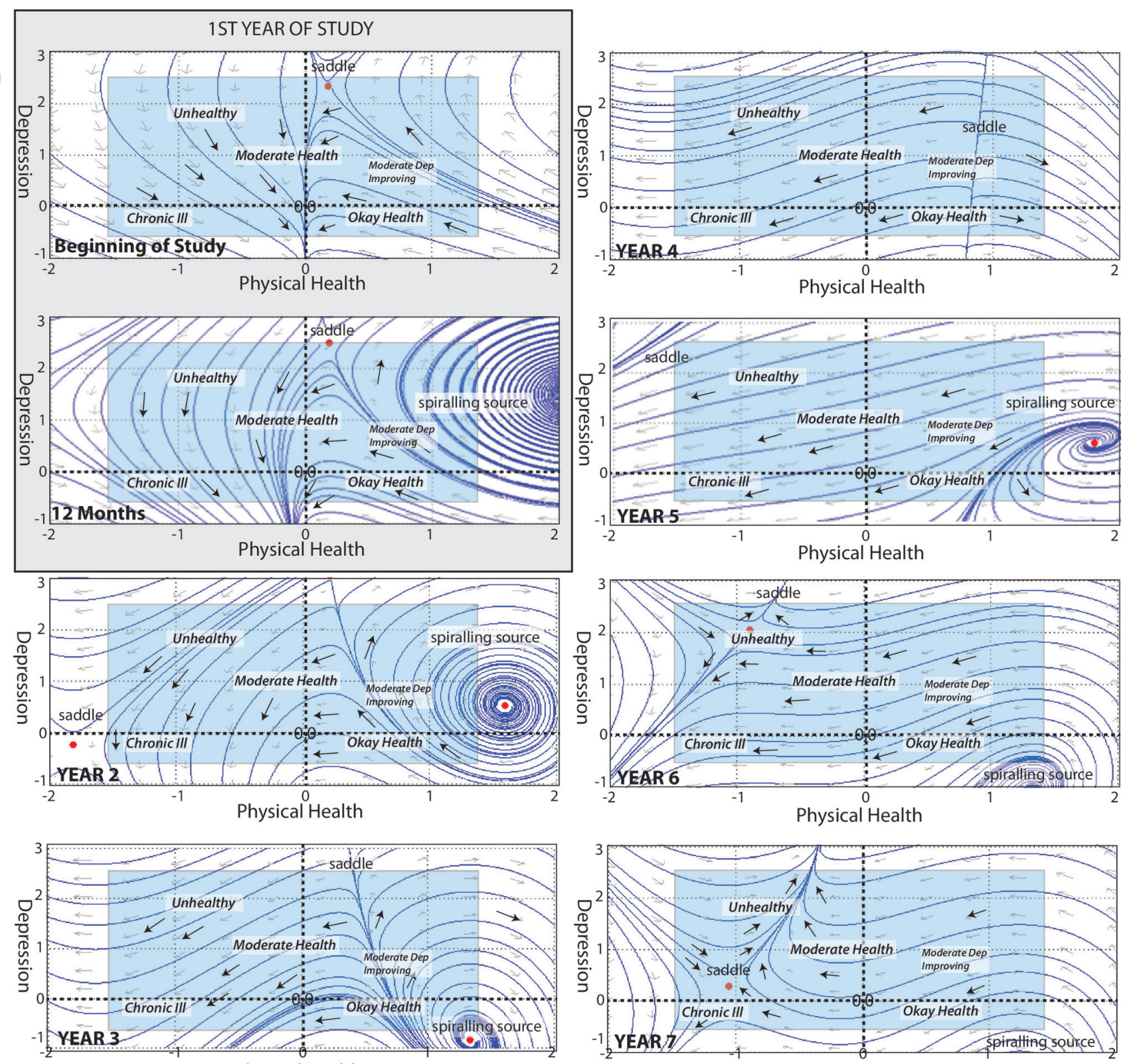

Physical Health

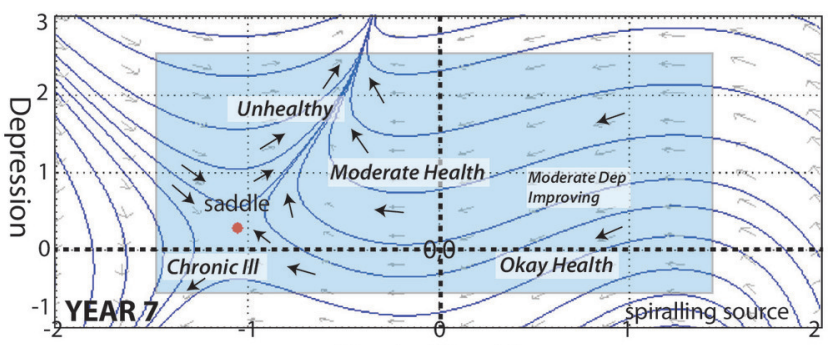

Physical Health

jep_13042_f3.eps 


\section{University Library}

\section{- MINERVA \\ A gateway to Melbourne's research publications}

Minerva Access is the Institutional Repository of The University of Melbourne

Author/s:

Castellani, B;Griffiths, F;Rajaram, R;Gunn, J

Title:

Exploring comorbid depression and physical health trajectories: A case-based computational modelling approach

Date:

2018-12-01

Citation:

Castellani, B., Griffiths, F., Rajaram, R. \& Gunn, J. (2018). Exploring comorbid depression and physical health trajectories: A case-based computational modelling approach. JOURNAL OF EVALUATION IN CLINICAL PRACTICE, 24 (6), pp.1293-1309. https:// doi.org/10.1111/jep.13042.

Persistent Link:

http://hdl.handle.net/11343/284602 